This is a self-archived version of an original article. This version may differ from the original in pagination and typographic details.

Author(s): Sundén, Henrik; Sauvée, Claire; Haukka, Matti; Stöm, Anna

Title: A Multi-Component Reaction towards the Development of Highly Modular Hydrogelators

Year: 2018

Version: Accepted version (Final draft)

Copyright: @ 2018 Wiley-VCH Verlag GmbH \& Co. KGaA, Weinheim

Rights: In Copyright

Rights url: http://rightsstatements.org/page//nC/1.0/?language=en

Please cite the original version:

Sundén, H., Sauvée, C., Haukka, M., \& Stöm, A. (2018). A Multi-Component Reaction towards the Development of Highly Modular Hydrogelators. Chemistry: A European Journal, 24(32), 8071-8075. https://doi.org/10.1002/chem.201800635 


\section{CHEMISTRY A European Journal}

\section{Accepted Article}

Title: A multi-component reaction towards the development of highly modular hydrogelators

Authors: Henrik Sundén, Claire Sauvée, Matti Haukka, and Anna Stöm

This manuscript has been accepted after peer review and appears as an Accepted Article online prior to editing, proofing, and formal publication of the final Version of Record (VoR). This work is currently citable by using the Digital Object Identifier (DOI) given below. The VoR will be published online in Early View as soon as possible and may be different to this Accepted Article as a result of editing. Readers should obtain the VoR from the journal website shown below when it is published to ensure accuracy of information. The authors are responsible for the content of this Accepted Article.

To be cited as: Chem. Eur. J. 10.1002/chem.201800635

Link to VoR: http://dx.doi.org/10.1002/chem.201800635 
WILEY-VCH

\title{
A multi-component reaction towards the development of highly modular hydrogelators
}

\author{
Claire Sauvée,${ }^{[\mathrm{a}]}$ Anna Ström, ${ }^{[\mathrm{a}]}$ Matti Haukka,${ }^{[\mathrm{b}]}$ and Henrik Sundén ${ }^{*[\mathrm{a}]}$
}

\begin{abstract}
Herein we report a multi-component reaction approach for the development of a new class of hydrogelators based on the OxoTriphenylHexanOate (OTHO) backbone. A focused library of OTHOs has been synthesized and their hydrogelation features evaluated. The two most potent hydrogelators were studied by rheology revealing different stiffness, appearances and thixotropic behaviours of the gels. The new gelators showcase the versatility of the OTHO backbone as a platform for the design of functionalized hydrogels with tunable gel properties.
\end{abstract}

Low molecular weight gelators (LMWGs) are molecules that have the ability to self-assemble into three-dimensional (3D) networks within the solvent to form a gel. The supramolecular organization of the gelators is driven by intermolecular interactions such as hydrogen bonding, $\pi-\pi$ interactions and van der Waals forces. This spontaneous self-assembly process has emerged as an important way to develop functionalized materials, as demonstrated by the broad range of LMWGs that have been reported over the past several decades. ${ }^{[1]}$ The field of LMWGs is currently expanding due to their potential use in numerous applications such as drug delivery, ${ }^{[2]}$ tissue engineering ${ }^{[3-5]}$ and as scaffolds for 3D cell cultures. ${ }^{[6,7]}$

Despite the large number of LMWGs reported in the literature, their gelation abilities/properties are still difficult to predict ${ }^{[1]}$ and the linear synthesis of most gelator scaffolds severely restricts the fine-tuning of the gelator functions, making their synthesis costly and time consuming. In this respect, multicomponent reactions where individual components can be varied offers the possibility to access a diverse array of gelators for the systematic discovery of new gel functions and applications. Wang and co-workers reported a 4-component Ugi-reaction that was successfully used for the development of a library of peptoid compounds with organo- and hydrogelation features (Figure 1). Gels of these compounds were only obtained in water/DMSO and water/ethanol mixtures, which is not ideal for biological applications ${ }^{\left[{ }^{[8}\right.}$ Recently, we disclosed the multicomponent synthesis of OTHOs (Figure 1) and their ability to form gels in hydrocarbon-based solvents such

[a] Dr. C. Sauvée, Dr. A. Ström, Dr. H. Sundén

Chemistry and Chemical Engineering

Chalmers University of Technology

Kemivägen 10, 41296 Göteborg (Sweden)

E-mail: sundenh@chlamers.se

[b] Dr. M. Haukka

Department of Chemistry

University of Jyväskylä

P.O. Box 35, Fl-40014 University of Jyväskylä (Finland)

Supporting information for this article is given via a link at the end of the document. CCDC 1576039 contain the supplementary

crystallographic data for this paper. These data are provided free of charge by the Cambridge Crystallographic Data Centre.

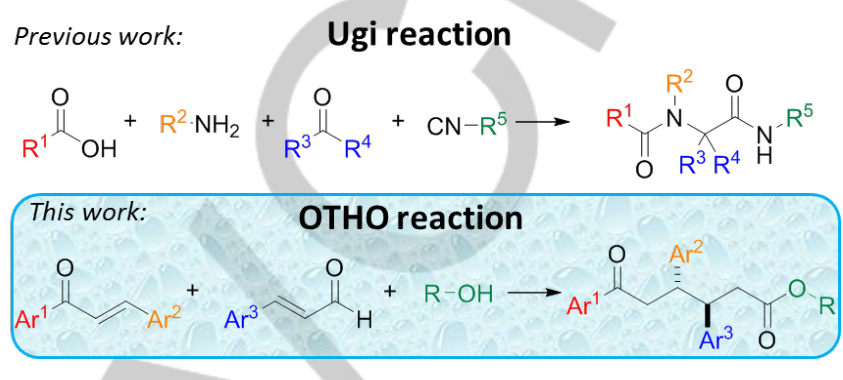

Figure 1. Multicomponent reactions for the design of hydrogelators.

as heptane and hexanes. ${ }^{[9-11]}$ Herein we report on the threecomponent synthesis of OTHO-based hydrogelators and their rheological properties.

In the quest to find an OTHO-based hydrogelator a small collection of compounds were synthesized (Scheme 1). The OTHO reaction is highly modular and in order to increase the hydrophilicity of the lipophilic OTHO backbone, hydrophilic groups were introduced on the four tunable positions of the OTHO backbone (the three aromatic rings $\mathrm{Ar}^{1}, \mathrm{Ar}^{2}, \mathrm{Ar}^{3}$ and the ester $\mathrm{R}$, see Scheme 1). The three aromatic rings are capable of forming $\pi-\pi$ interactions and are suspected to be the driving force behind the gelation of the OTHOs. ${ }^{[9]}$ Thus, introduction of pyridinium rings on the OTHO backbone will increase the water solubility and, potentially, also impact the gel properties by pyridinium- $\pi$ interactions. To this extent, pyridine $\mathrm{N}$-oxides are of particular interest as they are neutral substituents which can favor attractive pyridinium- $\pi$ interactions, in the absence of a counteranion that could otherwise affect the supramolecular self-assembly. ${ }^{[12,13]}$ In efforts to increase the water solubility of the OTHO derivative, the ester moiety was modified to incorporate a quaternary ammonium salt.

Derivatives 1-5 were obtained using the multi-component synthesis of OTHOs starting from the corresponding chalcones, cinnamaldehydes and alcohols (Scheme 1). ${ }^{[9]}$ After a facile filtration and washing protocol, compounds 1-5 were obtained in high purity. To introduce the $\mathrm{N}$-oxide function, pyridine OTHOs $1-$ 3 and $\mathbf{5}$ were oxidized to their corresponding pyridinium $\mathrm{N}$-oxide using $m$-CPBA to form $6-8$ and 10 , respectively. ${ }^{[14]}$ Methylation of the tertiary amine of $\mathbf{4}$ with methyl iodide afforded compound $\mathbf{9}$ (Scheme 1).

The inverted vial method (the system was defined as a gel if it was able to support its own weight upon inversion of the vial) was used to determine whether the compounds were capable of forming gels. The OTHO derivatives 1-10 were dissolved in hot water of different $\mathrm{pH}$ values in glass vials and then left to stand until they reached room temperature for the inversion test. In acidic $\mathrm{pH}(0.1 \mathrm{M} \mathrm{HCl})$, protonation of the pyridines or the tertiary amine increased the water solubility of compounds 2-5. At high 
WILEY-VCH

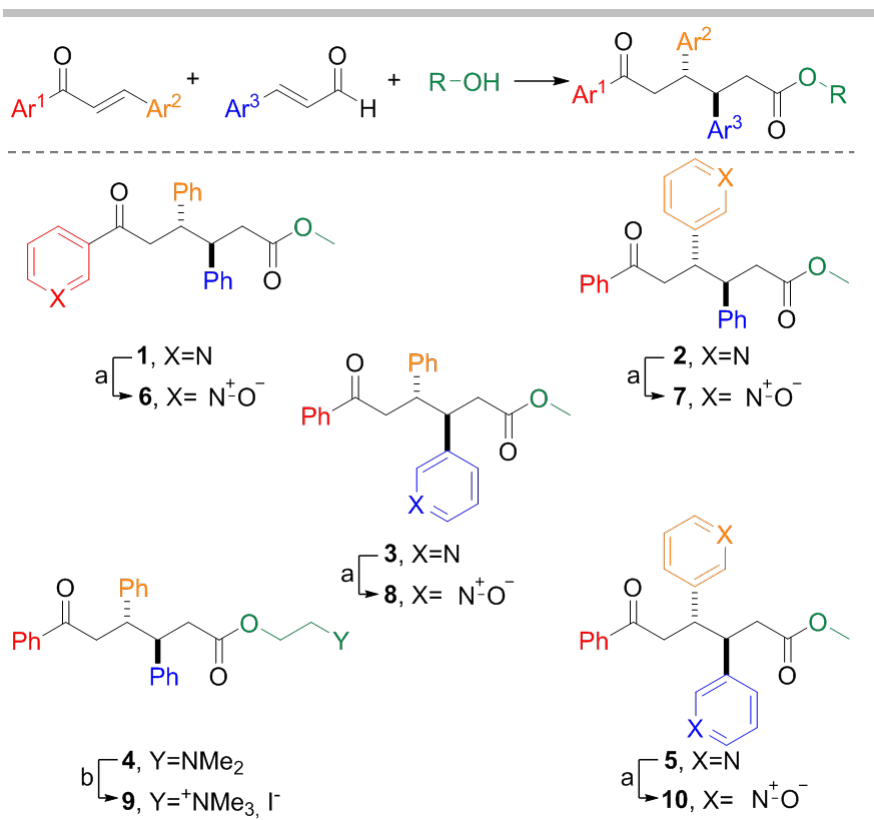

Scheme 2. The ionic liquid mediated OTHO reaction from a chalcone, an $\alpha, \beta$ unsaturated aldehyde and a primary alcohol. Compounds synthesized 1-10. Conditions: a) m-CPBA, $\mathrm{CHCl}_{3}$ b) $\mathrm{Mel}$, DCM.

temperatures $\left(>90{ }^{\circ} \mathrm{C}\right)$, only compound 1 remained insoluble (Table 1). Under acidic conditions, gels were obtained for compounds 3, 4, 8 and 9 while compounds 8 and 9 also formed gels at neutral $\mathrm{pH}$ (Figure 2). A much slower gelation (several hours) was observed for compound 3 , that formed a gel at $\mathrm{pH}=1$ and temperatures $<5^{\circ} \mathrm{C}$.

This suggests that, for compounds 3 (protonated at $\mathrm{pH}=1$ ) and $8($ at $\mathrm{pH}=7)$, pyridinium- $\pi$ interactions involving the aromatic ring $\mathrm{Ar}^{3}$ (Scheme 1) enhance the gelation capacity allowing gels to form at concentrations as low as $0.2 \mathrm{wt} \%$. The introduction of two pyridine $\mathrm{N}$-oxide on the backbone made compound $\mathbf{1 0}$ too water soluble for any gelation to be detected even at $5 \mathrm{wt} \%$. However, for compounds 2, 6 and 7, no gels were formed, indicating that the pyridinium- $\pi$ interactions involving $\mathrm{Ar}^{1}$ and/or $\mathrm{Ar}^{2}$ (Scheme 1), interfere with the gelation mechanism in water by favoring intermolecular interactions that are detrimental to the molecular self-assembly into a gel network. Compound 6 self-assembled into crystals (needles) that were resolved by X-ray crystallography (SI-Fig1). The crystal structure confirmed the presence of Tshaped pyridinium- $\pi$ and parallel pyridinium-pyridinium interactions. ${ }^{[15]}$ Moreover, two hydrogen bonds between the $N$ oxide and adjacent hydrogen atom are organized in a $R_{2}^{2}(8)$-type pattern. ${ }^{[16]}$ It is not unlikely that similar type of interactions are present in the gel network of compound 8.

As both OTHO derivatives 8 and $\mathbf{9}$ form gels under semiphysiological conditions, these gelators were further evaluated.

Compound $\mathbf{8}$ was able to form a hydrogel in concentrations ranging from 0.2 to $1 \mathrm{wt} \%$ at room temperature. For concentrations of $>0.3 \mathrm{wt} \%$, gelation occurred within 5 minutes. However, at a concentration of $0.2 \mathrm{wt} \%$ the onset of gelation was slower and the gel was obtained after standing for a few hours. At higher concentrations ( $>1 \mathrm{wt} \%$ ), compound 8 could no longer be fully dissolved with heating. To the best of our knowledge, compound $\mathbf{8}$ is the first LMWG based on pyridine $\mathrm{N}$-oxide; only polymer gels of poly(vinylpyridine $\mathrm{N}$-oxide) have been previously
Table 1. : Gelation tests at room temperature of compounds 1-10 using the inverted vial test at different $\mathrm{pH}$ values and compound concentrations.

\begin{tabular}{|c|c|c|c|c|}
\hline Compound & $\mathrm{pH}=1$ & $\mathrm{pH}=7$ & {$[g e l]_{\min }(w t \%)$} & $\mathrm{T}_{\text {gel/sol }}\left({ }^{\circ} \mathrm{C}\right)$ \\
\hline 1 & I & I & & \\
\hline 2 & I & 1 & & \\
\hline 3 & G [a] & I & 0.8 & \\
\hline 4 & G & 1 & 0.4 & \\
\hline 5 & S & T & & \\
\hline 6 & $P$ & C & & \\
\hline 7 & $P$ & $P$ & & \\
\hline 8 & G & G & $0.2,{ }^{[b]} 0.6^{[b]}$ & $65-85^{[\mathrm{d}]}$ \\
\hline 9 & G & G & $0.2,{ }^{[b]} 0.6^{[c]}$ & $50-70^{[e]}$ \\
\hline 10 & $S$ & $\mathrm{~S}$ & & \\
\hline
\end{tabular}

[a] Gel forms at $\mathrm{T}<5^{\circ} \mathrm{C}$ over several hours and is not stable at rt. [b] $\mathrm{pH}=7$. [c] $\mathrm{pH}=1(0.1 \mathrm{M} \mathrm{HCl}) . \mathrm{T}_{\text {gel/sol }}$ were measured at $\mathrm{pH}=7$, concentrations ranging from [d] 0.3 to $0.9 \mathrm{wt} \%$ and [e] 0.6 to $1 \mathrm{wt} \%$.

reported. ${ }^{[17]}$ For compound $\mathbf{9}$, gelation was observed at concentrations ranging from 0.6 to $1 \mathrm{wt} \%$. At concentrations $<0.6$ $w t \%$, a mixture of particles was observed indicating the occurrence of aggregation. However, the number of particles and/or the interparticular interactions were insufficient to form the $3 \mathrm{D}$ network of a gel.

As seen in Figure 2, the gels formed by compounds 8 and 9 have very different appearances; the gel of compound 8 is turbid whereas the gel of compound $\mathbf{9}$ is milky and white in color. The turbidity of the gels formed from compound 8 increases upon increasing the concentration of the gelator. The turbidity of both samples indicates that the gels contain large ( $\mu \mathrm{m}$ sized) structures that are able to scatter light. Optical microscopy images (SI-Fig 2) taken of the hydrogels and scanning electron microscopy (SEM) images of xerogels (Figure 3) confirm the presence of micro sized structures within both samples. Furthermore, the SEM images show that both compounds form fibrous networks composed of highly entangled fibers. Diameters of the fibers appear to be up to $5 \mu \mathrm{m}$. However, Mears et al. previously reported that due to the drying process required for sample preparation, SEM does not always show the primary network of fibers but instead depicts the aggregation of the fibers. ${ }^{[18]}$ The size of the fibers in the SEM images is therefore probably not representative of the size of the fibers in the gel state. It can also be observed that fibers of gel $\mathbf{8}$ appear to be aligned

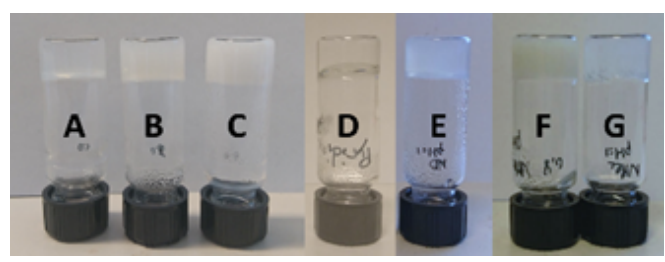

Figure 2. Pictures of hydrogels $\mathrm{A}$ ) compound 8 at $0.3 \mathrm{wt} \% \mathrm{pH}=7 \mathrm{~B}$ ) compound 8 at 0.6 wt $\% \mathrm{pH}=7 \mathrm{C}$ ) compound 9 at $0.6 \mathrm{wt} \% \mathrm{pH}=7 \mathrm{D}$ ) compound 3 at 1 wt $\%$ $\mathrm{pH}=1 \mathrm{E}$ ) compound 8 at 0.6 wt $\% \mathrm{pH}=1 \mathrm{~F}$ ) compound 9 at 0.8 wt $\% \mathrm{pH}=1 \mathrm{G}$ ) compound 4 at $0.6 \mathrm{wt} \% \mathrm{pH}=1$. 
WILEY-VCH

\section{COMMUNICATION}
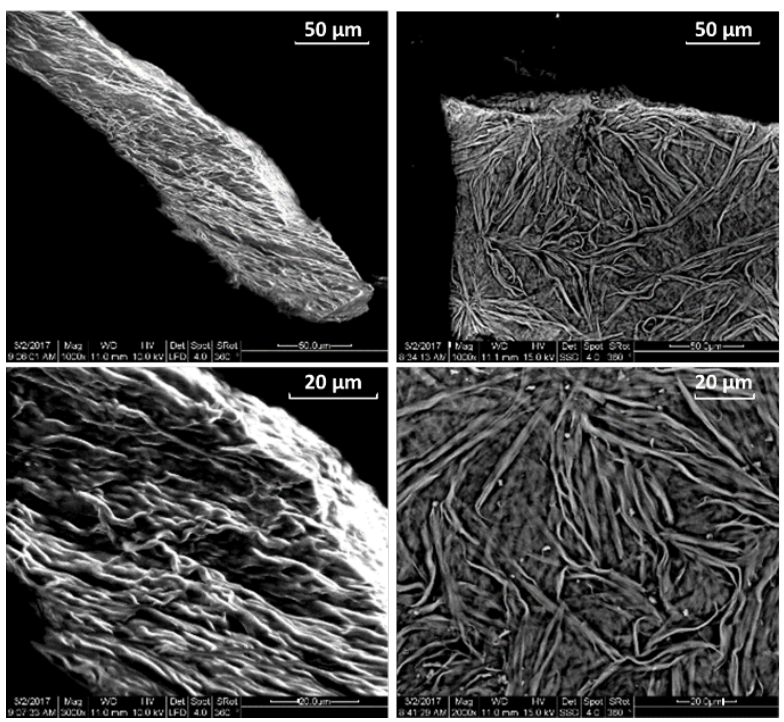

Figure 3. SEM images of xerogel of compound 8 formed at $0.5 \mathrm{wt} \%$ (left) and xerogel of compound 9 at 1 wt \% (right) at different magnitudes.

parallel to each other whereas fibers in gel $\mathbf{9}$ arranged around centers in star-like patterns. Optical micrographs of compound $\mathbf{9}$ (SI-Fig 2) confirmed that fibers organized around nucleation points. Polarized light micrographs of compound $\mathbf{8}$ and $\mathbf{9}$ (SI-Fig 3 and 4) showed thermoresponsive ordered structures whose order was lost upon increase of temperature $\left(>70^{\circ} \mathrm{C}\right.$ for compound 8 and $>100^{\circ} \mathrm{C}$ for compound $\mathbf{9}$ ).

The temperatures at which the gels of compounds $\mathbf{8}$ and $\mathbf{9}$ transitioned from gels to sols ( $T_{\text {gel/sol }}$ ) were determined using the inverted vial method. The temperature was increased until the gel melted and could no longer support its own weight upon inversion of the vial. For both compounds, $T_{\text {gel/sol }}$ was concentration dependent. Compound 9 had overall lower gel to solution transition temperatures compared to compound 8. (Table 1). It is worthwhile noting that the transition from gel to a clear solution required much higher temperatures than the original solution-togel transition. This observation is supported by a temperature sweep of a $0.3 \mathrm{wt} \% \mathrm{gel}$ of compound $\mathbf{8}$, which shows a $\mathrm{T}_{\text {sol/gel }}$ of $36{ }^{\circ} \mathrm{C}$ whereas $\mathrm{T}_{\text {gel/sol }}$ is much higher (about $65^{\circ} \mathrm{C}$, SI-Fig 6). In addition, the images taken of compounds $\mathbf{8}$ and $\mathbf{9}$ under crosspolarized light show that different amounts of ordered structures were present depending on whether the sample was cooled or heated (SI-Fig 3 and 4). This phenomenon is often referred to as thermal hysteresis and is common in network formations involving several steps.

The rheological properties of the gels were investigated in more detail using dynamic shear oscillation. The storage modulus $\left(G^{\prime}\right)$ and loss modulus ( $\left.G^{\prime \prime}\right)$ of the gels were measured as a function of temperature, frequency, compound concentration and strain. The frequency sweeps at $\mathrm{pH}=7$ (Figure $4 \mathrm{a}$ ) and $\mathrm{pH}=1$ (SI-Fig 7) show that $G^{\prime}$ is about one order of magnitude larger than $G$ " for all gels. A difference between $G^{\prime}$ and $G^{\prime \prime}$ around one order of magnitude has been observed for other networks composed of fibrillary entanglements e.g. nanofibrillated cellulose ${ }^{[19]}$ as well as other LMWGs. ${ }^{[20,21]}$ This feature is different from both covalently bound networks and physical networks e.g. with salt bridges where $G^{\prime}$ and $G$ " typically differ with two orders of magnitude. ${ }^{[22-24]}$ Moduli corresponding to compound 8 are largely independent on
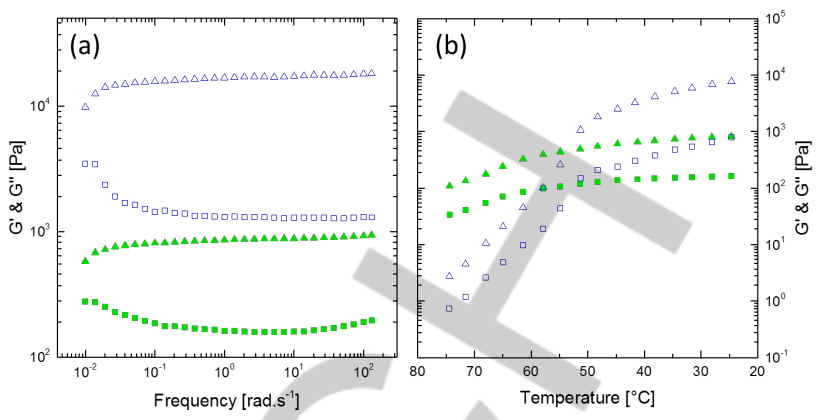

Figure 4. Storage (triangle) and loss (square) moduli of $0.6 \mathrm{wt} \%$ of compound 8 (blue) and compound $\mathbf{9}$ (green) as a function of frequency (a) and temperature (b). The frequency sweep was performed at a strain of $0.5 \%$ and $T=25^{\circ} \mathrm{C}$. The temperature sweep was performed at a frequency of $6.28{\mathrm{rad} . \mathrm{s}^{-1}}^{\text {and a strain of }}$ $0.5 \%$.

frequency and have a tan $\delta$ of approximately 0.05 thus correctly defined as a gel. ${ }^{[25]}$ The moduli of compounds 9 and 4 have a larger frequency dependence and with a somewhat higher tan $\delta$ of 0.4 to 0.15 , from low to high frequencies. The frequency sweep further show that the hydrogel formed from compound 9 shows a lower absolute value of $\mathrm{G}^{\prime}$ and $\mathrm{G}^{\prime \prime}$ compared to gel 8 at room temperature.

The variation of moduli as a function of temperature shows two regimes for both compound (Figure $4 \mathrm{~b}$ ). The increase in moduli correlates with the appearance of ordered structures as visualized using cross-polarized light (compound $\mathbf{8}, \mathrm{SI}-\mathrm{Fig} 2$ ). For compound 8, one can speculate whether the two different rates, at which $\mathrm{G}^{\prime}$ increases as a function of temperature, is related to a two-step formation of the gel a) self-aggregation of the molecules into fibers $\left(75^{\circ}\right.$ to $55^{\circ} \mathrm{C}$ ) followed by b) fibers organization into a 3D-network $\left(55^{\circ}\right.$ to $25^{\circ} \mathrm{C}$ ). For gels composed of compound $9, \mathrm{G}^{\prime}$ was already high when the sample was loaded onto the rheometer. Indeed, the presence of ordered structures was revealed via polarized light even at temperatures above $90{ }^{\circ} \mathrm{C}$ (SI-Fig 4).

The gel stiffness of compound $\mathbf{8}$ was measured at different concentrations $(0.3,0.5$ and $0.7 \mathrm{wt} \%)$. An increase in gel stiffness was observed upon increasing concentration (SI-Fig 8). A 0.5\% $(\mathrm{w} / \mathrm{v}) \mathrm{gel}$ in $\mathrm{D}_{2} \mathrm{O}$ was also submitted to a frequency sweep and the $\mathrm{G}^{\prime}$ and $\mathrm{G}^{\prime \prime}$ values obtained were very similar to those in $\mathrm{H}_{2} \mathrm{O}$ at the same concentration. This indicates that the gel structure is similar in both solvents and underlines that hydrogen bonds with the solvent are not the main contributor to the stiffness of the gel. ${ }^{[26]}$ With regards to stability, the gels can be stored at room temperature for several months without any apparent degradation (concentrations $>0.2$ and 0.6 wt \% for compounds 8 and $\mathbf{9}$, respectively).

Visual observations (Figure 5) showed that the gels formed from compound 9 did not reform after being subjected to vigorous shaking, not even if left to stand for 24 hours. Aggregates, which did not heal into larger homogeneous 3D structures, were observed. In contrast, gels of compound $\mathbf{8}$ were visually observed to reform after a short period of time ( $<5 \mathrm{~min}$, Figure 5$)$. The ability of compound $\mathbf{8}$ to reform rapidly after being subjected to high strain was confirmed by repeated strain steps, where the moduli was measured at 0.5 and $40 \%$ strain (Figure 5 ). At strain of $40 \%$, the storage modulus are considerably reduced and the storage and loss moduli are similar in magnitude. Once the strain is reduced to $0.5 \%$ the modulus increased rapidly. The moduli are 
WILEY-VCH

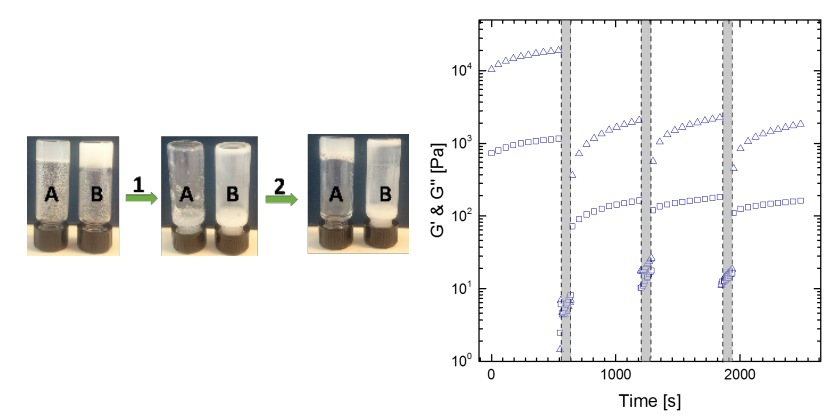

Figure 5. Pictures of $0.3 \mathrm{wt} \%$ hydrogel of compound 8 (A) and 0.6 wt $\%$ hydrogel of compound 9 (B) after 1) vigorous shaking and 2) stand $5 \mathrm{~min}$ at rt. Storage (triangle) and loss (square) moduli of $0.6 \mathrm{wt} \%$ of compound 8 , stepstrain measurement, at a strain of $0.05 \%$ (white areas) and a strain of $40 \%$ (grey area) and a frequency of 6.28 rad.s-1.

however higher prior to the first strain step at $40 \%$, compared to the reformed gels measured at a strain of $0.5 \%$. This suggest that there is an initial structure that is not reforming. As a side note, self-healing properties are a prerequisite for the development of injectable gels, ${ }^{[20]}$ therefore this could open up a range of applications of compound 8 since it self-heals and can easily be injected. In addition, gels can be formed in $0.1 \mathrm{M}$ tris-buffer, at both $\mathrm{pH} 7.4$ and 8.8 ( $\mathrm{SI}$-Fig 5) which further supports their possible use in biological applications.

In summary, we have developed two new hydrogelators based on the OTHO backbone. Gels with different properties were obtained showing that the OTHO backbone is suitable for the fine tuning of the gel properties such as self-healing or transparency. Furthermore, the scalable multicomponent reaction combined with the smooth purification of the reaction products (mainly filtrations) make the OTHO a highly modular and versatile new class of LMWGs Physically stable and non-peptide based, they are likely to exhibit a higher stability against enzymatic degradation; they could therefore be used for the design of functionalized and stimuli responsive hydrogels for biological applications. Current investigations are directed towards elucidating the self-assembly mechanism and its growth into a network to understand, and also predict, gelation of the OTHO derivatives.

\section{Acknowledgements}

We acknowledge the Swedish research council (VR and Formas) for funding. We would also like to express our gratitude to the Wenner-Gren foundation for providing the post-doctoral fellowship to CS and we thank the Wilhelm \& Martina Lundgren stiftelse and Stiftelsen Sigurd och Elsa Goljes minne for supporting the running costs of the project. Special thanks to Cassandra Fleming for proof-reading the manuscript.

Keywords: multicomponent reaction $\cdot$ gels $\cdot$ self-assembly $\bullet \mathrm{Pi}$ interactions $\cdot$ pyridine $\mathrm{N}$-oxide

[1] X. Du, J. Zhou, J. Shi, B. Xu, Chem. Rev. 2015, 115, 13165-13307.

[2] F. Rodríguez-Llansola, J. F. Miravet, B. Escuder, Chem. Commun. 2011, 47, 4706-4708.
[3] T.-Y. Cheng, M.-H. Chen, W.-H. Chang, M.-Y. Huang, T.-W. Wang, Biomaterials 2013, 34, 2005-2016.

[4] S. Ziane, S. Schlaubitz, S. Miraux, A. Patwa, C. Lalande, I. Bilem, S. Lepreux, B. Rousseau, J.-F. Le Meins, L. Latxague, et al., Eur. Cell. Mater. 2012, 23, 147-160.

[5] H. Wang, Z. Yang, Nanoscale 2012, 4, 5259-5267.

[6] N. Zanna, S. Focaroli, A. Merlettini, L. Gentilucci, G. Teti, M. Falconi, C. Tomasini, ACS Omega 2017, 2, 2374-2381.

[7] L. Latxague, M. A. Ramin, A. Appavoo, P. Berto, M. Maisani, C. Ehret, O. Chassande, P. Barthélémy, Angew. Chem. Int. Ed. 2015, 54, 45174521.

[8] H. P. R. Mangunuru, H. Yang, G. Wang, Chem. Commun. 2013, 49, 4489-4491.

[9] L. Ta, A. Axelsson, J. Bijl, M. Haukka, H. Sundén, Chem. - Eur. J. 2014, 20, 13889-13893.

[10] H. Sundén, L. Ta, A. Axelsson, JoVE J. Vis. Exp. 2015, e53213-e53213.

[11] A. Axelsson, L. Ta, H. Sundén, Catalysts 2015, 5, 2052-2067.

[12] S. Yamada, N. Yamamoto, E. Takamori, J. Org. Chem. 2016, 81, 1181911830.

[13] M.-O. M. Piepenbrock, G. O. Lloyd, N. Clarke, J. W. Steed, Chem. Rev. 2010, 110, 1960-2004.

[14] H. P. Kokatla, P. F. Thomson, S. Bae, V. R. Doddi, M. K. Lakshman, J. Org. Chem. 2011, 76, 7842-7848.

[15] M. L. Główka, D. Martynowski, K. Kozłowska, J. Mol. Struct. 1999, 474, 81-89.

[16] J. Bernstein, R. E. Davis, L. Shimoni, N.-L. Chang, Angew. Chem. Int. Ed. Engl. 1995, 34, 1555-1573.

[17] N. Hasirci, I. L. Kamel, V. N. Hasirci, Polymer 1990, 31, 2393-2396.

[18] L. L. E. Mears, E. R. Draper, A. M. Castilla, H. Su, Zhuola, B. Dietrich, M. C. Nolan, G. N. Smith, J. Doutch, S. Rogers, et al., Biomacromolecules 2017, 18, 3531-3540.

[19] O. Nechyporchuk, M. N. Belgacem, F. Pignon, Biomacromolecules 2016, 17, 2311-2320.

[20] K. J. Skilling, B. Kellam, M. Ashford, T. D. Bradshaw, M. Marlow, Soft Matter 2016, 12, 8950-8957.

[21] J. Ahn, S. Park, J. H. Lee, S. H. Jung, S.-J. Moon, J. H. Jung, Chem. Commun. 2013, 49, 2109-2111.

[22] S. B. Ross-Murphy, in Biophys. Methods Food Res. Crit. Rep. Appl. Chem., SCI Blackwell, London, 1984, pp. 195-290.

[23] A. Ström, E. Schuster, S. M. Goh, Carbohydr. Polym. 2014, 113, 336343.

[24] S. Ikeda, K. Nishinari, J. Agric. Food Chem. 2001, 49, 4436-4441.

[25] H. A. Barnes, A Handbook of Elementary Rheology, Univ. Of Wales, Institute Of Non-Newtonian Fluid Mechanics, Aberystwyth, 2000.

[26] T. R. Canrinus, F. J. Cerpentier, B. L. Feringa, W. Browne, Chem. Commun. 2017, 53, 1719-1722. 
WILEY-VCH

\section{Entry for the Table of Contents}

\section{COMMUNICATION}

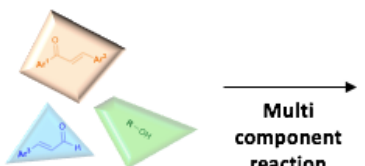

component
reaction
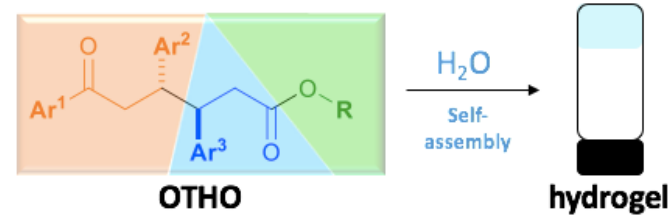

A multi component synthesis of hydrogelators has been developed enabling rapid screening and development of hydrogels with tailor-made properties.
Claire Sauvée, Anna Ström, Matti Haukka and Henrik Sundén*

Page No. - Page No.

A multi-component reaction towards the development of highly modular hydrogelators 